\section{Os cartazes dos protestos líquidos}

Posters of liquid protests

Helcius Batista PEREIRA (PUC-RJ) helcius@usp.br

Ariane Fermino SILVA (PUC-RJ) arianefermino@yahoo.com.br
PEREIRA, Helcius Batista; SILVA, Ariane Fermino. Os cartazes dos protestos líquidos. Entrepalavras, Fortaleza, v. 6, n. 2, p. 54-71, jul./ dez. 2016.

Resumo: O presente artigo tem como objetivo analisar amostras de cartazes dos protestos de 2013 realizados nas principais cidades brasileiras, na esteira da luta pelo "passe livre". Propomonos a estudar os cartazes, descrevendoos sob a perspectiva multissistêmica (CASTILHO, 2010). Os cartazes que aqui recolhemos para constituição do corpus são parte de um gênero textual e discursivo específico, conforme Bakhtin (2011). A pesquisa explora as mútuas interações estabelecidas entre o linguístico e o social por meio desse gênero, realizando análise quantitativa dos cartazes nos diversos níveis (do lexical ao pragmático-discursivo). Nosso trabalho se apoia nos conceitos de habitus e mercado linguístico (BOURDIEU, 2003) e de "modernidade líquida" (BAUMAN, 2001). Os resultados de nossa análise mostraram que: 1) o tema mais comum veiculado pelos cartazes refere-se ao ato de protestar, 2) apenas $40 \%$ deles são textos argumentativos e injuntivos, 3) os cartazes têm, em geral, apenas uma única frase, 4) em baixa frequência fazem uso de recursos não verbais; 5) os cartazes têm, em geral, frases de período simples; 6) apresentam baixo uso de verbos no imperativo; 7) servem pragmaticamente 
para declarar algo e provocar alguma reflexão daquele que o lê, mas apresentam baixo potencial reivindicatório. Todas essas características nos indicam que os cartazes dos protestos de 2013 guardam uma relação com os textos das redes sociais, aos quais estão conectados em tempo real, e são produto linguístico de uma geração que mantém em seu habitus as regras da "modernidade líquida".

Palavras-chave: Protestos de 2013. Cartazes de protestos. Análise multissistêmica.

Abstract: This article aims to analyze a corpus formed by sample of posters used in the Brazilian protests, called "Passe Livre", in 2013. Our study intents understand the posters under the multi-systemic perspective (Castilho, 2010). The posters are a kind of textual genre (Bakhtin, 2011). This work explores the mutual interactions between the language and the social facts, performing quantitative analysis of the posters at various levels (from the lexical to the pragmatic-discursive level). Our methodological pillars are the concepts of habitus and linguistic market (Bourdieu, 2003) and the concept of "liquid modernity" (Bauman, 2001). Our analysis showed that: 1) the most common theme of the posters refer to the act of protest, 2) only $40 \%$ of the posters are argumentative or injunctive texts, 3) the posters have, in general, only once sentence, 4) in low frequency, the posters have elements of the non-verbal languages, 5) the posters have, more often, simple phrases period, 6) imperative verbs are rare on those posters, and, finally, 7) most of the posters are for declaring something and do another reflect, but not to demand something. All these features indicate that posters have a relationship with the texts of social networks, to which are connected in real time, and are a linguistic product of the generation that has in your habitus the rules of the "liquid modernity".

Keywords: Brazilian protests. Posters of protests. Multi-systemic analysis.

\section{Introdução}

O presente trabalho tem por objetivo realizar análise de amostragem de cartazes dos protestos de 2013, buscando compreender no caso específico desses "produtos linguísticos", as interações mútuas entre o linguístico e o sociocultural.

Os protestos de junho de 2013, cujos cartazes procuramos analisar, foram capitaneados pelo chamado "Movimento Passe Livre" (doravante, MPL), que lutava - e ainda luta - pela tarifa zero no transporte público e, de uma maneira mais geral, pela questão da melhoria na mobilidade urbana, em especial a que atende à classe trabalhadora. Assim, sua "Carta de Princípios" defende o MPL de maneira independente de partidos, sindicatos, ONGs e outras instituições, tendo como pretensão agregar sua luta a outras vozes, declaradamente revolucionárias, que contestem a ordem vigente (MPL, sem data). Com essa proposta, os protestos de 2013, assim como os realizados em 2016, abarcaram diversas vozes de descontentamento, de matrizes ideológicas bastante diversas.

Para realizar a pesquisa que apresentamos aqui, apoiamo-nos em uma perspectiva de análise multissistêmica, conforme proposta 
v. 6 (2)

54-71

jul/dez

2016

de CASTILHO (2010). Essa perspectiva evita os recortes mutiladores do objeto linguístico, concebido como complexo e dinâmico. Assim, aqui nos aventuramos a seguir o roteiro de uma análise que perpasse avaliações dos sistemas lexical, gramatical, pragmático-semântico e discursivo, que se implicam mutuamente, atuando para que as interações se constituam.

Os exemplares de cartazes de protestos usados naquelas manifestações que recolhemos e analisamos foram aqui compreendidos como parte de um "gênero do discurso", no sentido empregado por Bakhtin (2011). São "tipos" de enunciados relativamente estáveis, por serem tributários de uma forma de expressão construída historicamente, e que ao mesmo tempo revelam características específicas da enunciação em que circulam (BAKHTIN, 2011, p. 261).

Para conciliar o linguístico e o social mostrando suas mútuas interações, apoiamo-nos em Bourdieu (2003), em especial os conceitos de "mercado" e "habitus" linguístico. Para completar a interpretação do contexto sociocultural em que os cartazes circularam, recorremos a Bauman (2001) e sua concepção acerca da "modernidade líquida".

Por fim, o presente trabalho encontra justificativa na necessidade de compreender, sob o ponto de vista linguístico, o movimento de protestos nas grandes capitais brasileiras que ainda se perpetua.

\section{Interpretações gerais sobre os protestos de 2013}

Muitas interpretações surgiram sobre o que de fato foram as manifestações de protestos de 2013. No calor da hora, muitos julgamentos foram feitos e depois refeitos. Quem não se lembra da condenação feita por Arnaldo Jabor, na Rede Globo, acusando os manifestantes de serem membros da classe média que não tinham uma causa pela qual lutar e, na sequência, sua mudança de posição, sugerindo que o movimento havia ganhado uma força política maior do que o de outros protestos.

Por questões de espaço, aqui não faremos um apanhado de todas as interpretações e seus matizes ideológicos. Seguiremos, no entanto, avaliações selecionadas, publicadas na obra Cidades Rebeldes, que aglutinou diversos entendimentos sobre os protestos, incluindo do MPL.

Dentre estas avaliações, gostaríamos de apontar a de Raquel Rolnik, docente e pesquisadora da área de Arquitetura e Urbanismo da USP. Ao apresentar a obra, Rolnik a associa a um terremoto "que 
perturbou a ordem de um país que parecia viver uma espécie de vertigem benfazeja de prosperidade e paz, e fez emergir não uma, mas uma infinidade de agendas mal resolvidas, contradições e paradoxos" (ROLNIK, 2013, p. 8). Suas motivações seriam diversas, como de fato, apontam os analistas que Cidades Rebeldes reuniu.

Em texto assinado pelo próprio MPL, há a interpretação de que as manifestações partem da demanda do Passe Livre que discute a isenção das tarifas do transporte, mas querem fundamentalmente a retomada do espaço urbano, ponto focal para a justiça social: "As catracas do transporte são uma barreira física que discrimina, segundo o critério da concentração da renda, aqueles que podem circular pela cidade daqueles condenados à exclusão urbana" (MPL, 2013, p. 15). A perspectiva de uma manifestação realizada por meio da "organização descentralizada" da luta permitiu superar a pauta do MPL, aglutinando outras insatisfações.

Maricato (2013), outro autor constante de Cidades Rebeldes, avaliou que o movimento foi ignorado por uma esquerda que não conseguiu ali identificar uma luta de classe e, ao mesmo tempo, por uma direita que estava acostumada a apostar tudo na especulação imobiliária e no assalto ao orçamento público. A questão da cidade, de sua ocupação, da agenda da reforma urbana, fundiária e imobiliária foi esquecida pelas políticas públicas em diversos níveis nos anos recentes. A insatisfação em torno do uso e ocupação da cidade estaria, então, na raiz dos movimentos de 2013.

Para Vainer (2013), também constante do Cidades Rebeldes, as desigualdades impostas na exploração do espaço urbano estão na base dos movimentos de 2013, situação que foi reforçada pelos megaeventos (Copa e Olimpíadas):

Não há como não reconhecer a conexão estreita entre os protestos em curso e o contexto propiciados pelos intenso e maciços investimentos urbanos associados à Copa do Mundo de 2014 e, no caso do Rio de Janeiro, também aos Jogos Olímpicos de 2016 (VAINER, 2013, p. 37).

A cidade havia se tornado neoliberal, por seus gestores, e a resposta teria vindo das ruas.

Por fim, gostaríamos de mencionar a avaliação de Sakamoto, constante em Cidades Rebeldes. O analista político e jornalista aponta a relação entre os protestos e as mídias sócias que seriam muito mais do que espaços de marketing pessoal ou de divulgação de informações. 
V. 6 (2)

54-71

jul/dez

2016

Sakamoto (2013) afirma que as mídias sociais são ferramentas de construção e de reconstrução da realidade. As várias vozes que insuflaram as ruas e os espaços virtuais, como o Facebook, portaram descontentamento sobre o sistema representativo político que nunca deu solução a muitos problemas.

Entretanto, Sakamoto avalia que, por trás das vozes dos manifestantes, haveria um certo vazio sobre o que de fato desejavam; experimentavam o poder da manifestação, mas não sabiam que rumo deviam tomar:

Muitos desses jovens estão descontentes, mas não sabem o que querem. Apenas o que não querem. Neste momento, por mais agressivos que sejam, boa parte deles está em êxtase, alucinada com a diversão que é estar na rua e com o poder que acreditam ter nas mãos. Mas ao mesmo tempo, com medo. Pois cobrados de uma resposta sobre sua insatisfação, no fundo, no fundo, conseguem perceber apenas um grande vazio (SAKAMOTO, 2013, p. 100).

Frente a esse panorama geral interpretativo sobre o movimento, podemos passar a conhecer alguns dos trabalhos mais propriamente linguísticos e discursivos sobre os cartazes de protestos, o que faremos na próxima seção.

\section{Análises linguísticas e discursivas dos protestos de 2013.}

Iniciamos a seção sobre as análises linguísticas dos protestos com três artigos publicados na Revista de Língua Portuguesa, de circulação em bancas pela cidade. Essa edição foi publicada ainda no calor dos protestos, em agosto de 2013. O primeiro deles é do linguista e analista do discurso Sírio Possenti - que será referido adiante como Possenti (2013); o segundo, do jornalista Edgard Murano - que será tratado a seguir como Murano (2013); e o terceiro, do também jornalista Marcílio Godói - mencionado nesta seção como Godói (2013).

Possenti (2013) começa por apontar o amadorismo na criação dos cartazes, evidenciando que foram feitos em última hora e sem a coordenação ou liderança, marca dos protestos naquela altura. Analisando os cartazes, o professor e pesquisador encontra alguns que só se explicam por características pessoais do manifestante, como o "Olha minha cara de vândala", empunhado por um pai que levava uma criança no colo, obviamente distante de qualquer característica que a pudesse ligar ao vandalismo. Outros exploram as citações - alteradas 
ou não - como o "verás que um filho teu não foge à luta". Outros, constroem o seu sentido explorando o conhecimento de mundo e de memória, como o "O governo se inspire no Neymar e caia", que exige daquele que lê conhecimento sobre Neymar e algumas críticas quanto ao seu modo de jogar futebol. Dentre as relações intertextuais estabelecidas pelos cartazes analisados por Possenti, um chama-lhe a atenção: a que o cartaz "+ Pão, - Circo" estabelece com a frase latina "panem et circenses", associada ao Estado Romano. O manifestante faz uma correção, colocando um lado como o "certo" (o pão) e o outro como o "errado" (o circo).

Murano (2013) aponta a relação em que os cartazes sempre estabelecem com discursos enunciados anteriormente. Essa relação se dá através da paródia, da crítica e da sátira, sendo comum a inversão dos sentidos. Essa inversão é, para Murano, uma marca retórica evidente nos cartazes dos protestos de junho de 2013. Por fim, o jornalista aponta a incorporação da linguagem e dos mecanismos dos cartazes de protestos em peças publicitárias, como a que foi feita por uma indústria de carros a partir do slogan "vem pra rua".

Godoi (2013) analisou amostras dos cartazes e apontou suas principais características: o tom de irreverência e de provocação, em metodologia que se pretende viral. Essas características estariam presentes, por exemplo, na opção feita em um dos cartazes que tinha como slogan "Meu cu é laico" ao invés da formal "Pelo fim do preconceito". Também estaria presente na modificação de palavra de ordem da antiga Passeata dos Cem Mil "O gigante acordou" imposta em julho como "O gigante acordou puto". A variação regional também teria o seu espaço nas manifestações em frases como "É peia", estampada em um cartaz no Ceará. O próprio evento de protesto foi "avacalhado", segundo Godói, em um cartaz que simplesmente anunciava que o suposto manifestante estava vendendo um carro.

Mais distantes temporalmente dos eventos de meados de 2013, Brait; Lopes-Dugnani (2014) realizam análise bastante pertinente do movimento e dos seus discursos, seguindo o arcabouço teórico bakhtiniano. As autoras exploram as interações entre o verbal e o visual em algumas imagens sobre os eventos de 2013, garimpadas nas mídias sociais, contendo cartazes. Partem da premissa de que os materiais que analisam constituem formas de enunciação pertencentes às manifestações em si, como também à atuação das tecnologias contemporâneas nesses eventos. 
v. 6 (2)

54-71

jul/dez

2016

A partir desse ponto, as autoras mostram a relação intertextual entre cartazes de protestos que enunciam que o Brasil ou o país estava em obras - e as "placas de sinalização" usadas em obras de espaços físicos. Identificam aí o fio discursivo do "discurso do trabalho": são "[...] mudanças concretizadas sob a forma de conserto/reparo e/ou construção necessária para o estabelecimento ou retorno a uma ordem específica" (BRAIT; LOPES-DUGNANI, 2014, p. 121).

Mas a diversidade de discursos dos cartazes é marca daqueles protestos. Parte dos cartazes analisados pelas autoras sugerem um "discurso de ordem" que requer mudanças pacíficas, realizadas como "correções de rumos". Outra parte, no entanto, associa esta mudança à imagem da máscara - tomada da HQ e do filme "V de Vingança", sugerindo discursivamente a necessidade do confronto. Por fim, as autoras não deixam de notar outros fios discursivos, como o "discurso nacionalista" (BRAIT; LOPES-DUGNANI, 2014, p. 129).

\section{Quatro pilares teóricos de nossa pesquisa}

A presente pesquisa se sustentou em quatro pilares que, em nossa concepção, podem dialogar para nos ajudar a atingir os objetivos de análise de amostra dos cartazes dos protestos de 2013. O primeiro pilar encontramos na análise multissistêmica proposta pelo professor Ataliba Teixeira de Castilho, aqui resenhadas a partir de Castilho (2010).

A língua, nessa teoria, é entendida como sendo formada por multissistemas. O primeiro desses sistemas é o lexical e a este é associado o processo de lexicalização, que diz respeito à criação de palavras através das quais expressamos categorias cognitivas e traços semânticos. No uso da língua, a lexicalização atua quando conectamos o léxico (do inventário pré-verbal) ao vocabulário (entendido como um inventário pós-verbal). Outro sistema da língua é o semântico e o processo a ele associado é a semanticização, entendida como o mecanismo de criação de sentidos que é administrado mais uma vez pelo dispositivo sociocognitivo. Outro sistema é o discurso, ao qual se relaciona a chamada discursivização, através da qual se dá a criação de textos, novamente administrada pelo dispositivo sociocognitivo. Por fim, há o sistema da gramática, e a este se associa a gramaticalização, também conduzida pelo dispositivo sociocognitivo. A gramática aqui é entendida como entidade a posteriori que se constitui no uso. Estes sistemas não estão dispostos em uma relação de dependência, nem 
estão estruturados de forma hierárquica, de modo que um não governa o outro. Há, no entanto, a possibilidade de haver interfaces entre estes sistemas.

Entendemos que esta forma de ver a língua estabelece grande diálogo com a concepção de "Gênero do Discurso" que encontramos em Bakhtin (2011). Gêneros são entendidos nessa perspectiva como enunciados relativamente estáveis, construídos historicamente, e que funcionam em um dado campo de utilização da língua:

Esses enunciados refletem as condições específicas e as finalidades de cada referido campo não só por seu conteúdo (temático) e pelo estilo da linguagem, ou seja, pela seleção de recursos lexicais, fraseológicos e gramaticais da língua, mas acima de tudo, por sua construção composicional (BAKHTIN, 2011, p. 261).

A Língua só é, em última instância, colocada em uso através dos gêneros. Como falantes de uma dada língua, dispomos de um rico repertório de gêneros orais e escritos, estes últimos adquiridos pela via do letramento. Os mais cotidianos são-nos fornecidos de forma idêntica à maneira como a língua nos é oferecida, sem uma sistematização do tipo que a escola nos apresenta (ou tem condições de apresentar). O contato que temos com nossa língua materna só se dá assentada nos gêneros discursivos que organizam nosso discurso. Se não existissem, se fosse necessário criá-los a cada interação, segundo Bakhtin, seria quase impossível a comunicação (BAKHTIN, 2011, p. 283).

Através de todos os subsistemas que a constituem e por meio dos gêneros discursivos, a língua é impactada e impacta o social. Entendemos que nossa análise não seria completa se nos limitássemos ao arcabouço da Linguística, conforme recorte convencional. Assim buscamos teorias sociais que pudessem melhor nos ajudar os contextos em que os textos e discursos são produzidos e as formas como estes atuam sobre o social. Dois teóricos da Sociologia nos pareceram adequados para esta análise. O primeiro é deles é Pierre Bourdieu, que aqui apresentaremos através de Bourdieu (2003). Para este autor os produtos linguísticos são os resultados de um habitus e de um "mercado linguístico". O habitus é o dispositivo construído historicamente e internalizado pelos indivíduos desde as suas primeiras inserções sociais, que contém todas as disposições que regem a sanção e as escolhas linguísticas prestigiadas (tomadas por legítimas). Portanto, é uma categoria social, estando associado a um determinado grupo social. É o habitus que permite que 
V. 6 (2)

54-71

jul/dez

2016

o indivíduo escolha quais produtos linguísticos (formas linguísticas e os discursos) se deve oferecer em um determinado mercado linguístico. Este mercado é formado por agentes com diferentes quantidades de "capital linguístico", ou seja, de capital social para impor seus produtos linguísticos como "legítimos" (aceitos por todos como tal), aferindo lucros simbólicos distintos. Em nossa interpretação, o habitus é parte do dispositivo sociocognitivo a que se refere Castilho na proposta de análise multissistêmica que mencionamos anteriormente.

Por último, buscamos uma interpretação sociológica sobre a contemporaneidade. E encontramos rico apoio em Bauman (2001). Para este autor, a marca que perpassa várias faces da vida social na modernidade é sua fluidez, que contrasta com a visão "pesada" de gerações passadas que agiam para tornar duradouras seus vínculos pessoais, trabalhistas e nas mais diversas inserções que faziam socialmente. A fluidez é a característica fundamental da relação dos indivíduos com outros indivíduos no estabelecimento das amizades e das relações ligadas ao amor e sexo. Também são fluídas as relações que temos com o trabalho e nossas ações enquanto consumidores. Na visão de Bauman:

Chegou a vez da liquefação dos padrões de dependência e interação. Eles são agora maleáveis a ponto que as gerações passadas não experimentaram e nem poderiam imaginar; mas como todos os fluidos, eles não mantêm a forma por muito tempo (BAUMAN, 2001, p. 14).

A liquidez é, ao nosso ver, uma das componentes dos dispositivos do habitus do homem moderno e que impactam seus produtos linguísticos.

\section{Nossa metodologia}

Para a pesquisa que aqui apresentaremos, constituímos um corpus de análise com cartazes que circularam nos protestos em junho de 2013 e que marcaram a História do Brasil. Esse corpus foi formado com 50 diferentes cartazes retirados de sites e das redes sociais, e escolhidos aleatoriamente.

Sobre tais materiais, procuramos mapear quantitativamente as características dos cartazes, em uma perspectiva que perpassa os sistemas da língua, conforme expomos em nossa metodologia: 1) identificamos seus principais temas e tópicos; 2) mapeamos as tipologias textuais que 
neles são predominantes (se narrativos, injuntivos, argumentativos, etc.); 3) dimensionamos pela quantidade de frases e orações que dispõe a sua extensão; 4) mapeamos o uso de linguagens não-verbal ou de signos pertinentes aos códigos semióticos digitais; 5) avaliamos usos de palavras da linguagem coloquial e os empréstimos linguísticos, de modo a refletir sobre algumas das escolhas lexicais mais comuns nos cartazes; 6) inventariamos os tipos de frases mais frequentemente usados nesse textos (se frases com sentenças simples, se frases com sentenças coordenadas, se há estrutura de subordinação; se se fez uso de frases nominais, sem a estrutura de um sintagma verbal; 7) identificamos também procedimentos sintáticos (e discursivos) como o uso de vocativos, de verbos no imperativo e, por fim, 8) constituímos a matriz que cruza atos ilocucionais e perlocucionais associados aos cartazes que formaram nossos corpus.

\section{Que resultados encontramos?}

Seguindo nossa metodologia, avaliamos em nosso material, em primeiro lugar, os aspectos de conteúdo dos cartazes de protestos que analisamos. Assim, deparamo-nos com a necessidade de compreender as "demandas" abordadas pelos cartazes, o que podemos ver na Tabela 1.

Tabela 1 - Avaliação de Conteúdos e Tópicos dos Cartazes

\begin{tabular}{|l|l|l|}
\hline & Qtd. & $\%$ do Total \\
\hline Educação & 8 & $16,0 \%$ \\
\hline Saúde & 7 & $14,0 \%$ \\
\hline Violência & 6 & $12,0 \%$ \\
\hline Política & 10 & $20,0 \%$ \\
\hline Transporte & 5 & $10,0 \%$ \\
\hline Manifestação & 18 & $36,0 \%$ \\
\hline Corrupção & 5 & $10,0 \%$ \\
\hline Total & 50 & $100,0 \%$ \\
\hline
\end{tabular}

A observação da tabela acima nos deixa claro que existe uma diversidade de temas demandados pelos cartazes que recolhemos, evidenciando uma falta de uma unidade temática nas reivindicações. Nisso, os materiais que analisamos comprovam observações feitas por Brait; Lopes-Dugnani (2014) quanto à diversidade dos discursos apresentados nas manifestações. Também confirmam a análise de Rolnik (2013) acerca da existência de muitas agendas, por vezes contraditórias.

Entretanto, o que muito nos chamou atenção é que o tema 
V. 6 (2)

54-71

jul/dez

2016

mais comum é a própria manifestação ou o simples fato de poder se manifestar, com 36\% dos protestos. Esses cartazes não pretendem propriamente requerer algo, mas marcar posição sobre um tema. Seguem alguns exemplos':

(1) Seja a mudança que você quer no Brasil.

(2) Amor a Pátria não tem fronteiras².

(3) Os movimentos e o povo se uniram: um por todos e todos por um no combate a corrupção.

(4) Não é pelo "busão" é pela nação.

Os resultados não confirmam as expectativas criadas em torno do tema "transporte" que teria originado o processo de protesto em 2013, como vimos em MPL (2013), Vainer (2013) e Maricato (2013). A tabela acima mostra que somente $10 \%$ tinham essa motivação.

Voltando nosso olhar para a estrutura textual e a questão dos estilos usados nos materiais que constituem nosso corpus, procuramos analisar quais eram os "tipos de textos" predominantemente mais frequentes. O resultado pode ser visto na Tabela 2.

Tabela 2 - Tipologia textual predominante

\begin{tabular}{|l|l|l|}
\hline & Qtd. & $\%$ do Total \\
\hline Narrativos & 15 & $30,0 \%$ \\
\hline Descritivos & 0 & $0,0 \%$ \\
\hline Expositivos & 15 & $30,0 \%$ \\
\hline Argumentativos & 3 & $6,0 \%$ \\
\hline Injutivos & 17 & $34,0 \%$ \\
\hline Total & 50 & $100,0 \%$ \\
\hline
\end{tabular}

Como podemos ver na tabela acima, os textos injuntivos ou argumentativos somam $40 \%$ dos casos, como os apresentados nos exemplos (5) e (6). Mais interessante ainda é notar que, em uma manifestação tradicional, com o intuito de sugerir, convencer, persuadir

1 Se somarmos a quantidade em cada demanda encontrada o resultado será maior que os 50 cartazes analisados, isso porque alguns cartazes abordam e favorecem mais de uma demanda, como os exemplos apresentados em (3) e (4), um referindose a "manifestação" e "corrupção" e o outro a "transporte" e "manifestação" respectivamente.

2 Mantivemos as frases dos cartazes tal qual foram apresentadas por seus autores. Assim (2) e (3) foram produzidas sem crase, razão pela qual apresentamos assim tais ocorrências. 
e/ou levar a aceitar algo, esses tipos de textos deveriam ser os mais frequentes. Mas 60\% dos textos não são assim, apresentando estruturas narrativas ou expositivas, como as apresentadas em (7) e (8).

(5) Passe livre já!

(6) \#Vemprarua.

(7) Somos os filhos da revolução.

(8) Falta saúde, falta educação, falta dignidade mas sobra corrupção.

A análise que realizamos da estrutura composicional dos cartazes de protestos. Nossos resultados acerca deste ponto aparecem na Tabela 3 a seguir.

Tabela 3 - Estrutura textual: dimensão do texto

\begin{tabular}{|l|l|l|}
\hline & Qtd. & $\%$ do Total \\
\hline Somente uma frase & 43 & $86,0 \%$ \\
\hline Mais de uma frase & 7 & $14,0 \%$ \\
\hline Total & 50 & $100,0 \%$ \\
\hline
\end{tabular}

O cartaz de protesto deve, obviamente, relativamente a outros gêneros, ser simples e claro, com textos curtos e impactantes. Nesse sentido, apresenta certas semelhanças com a postagem em redes sociais. Nossos resultados parecem comprovar esses procedimentos. A maior parte deles, como os exemplos (9) e (10), são constituídos de uma única frase, que, com procedimentos, como ironia, intertextualidade com diversos outros discursos 3 , buscam impactar o espectador da manifestação. Raros são os exemplos que fogem dessa dimensão reduzida, como (11) e (12).

(9) PEC 37 NÃO.

(10) O gigante não está mais adormecido.

(11) A justiça não me olha porque é cega! Mas o seu dinheiro na carteira...ela enxerga!

(12) Não vamos nos cansar! Não vamos nos calar! Até o Brasil mudar!

Outro ponto que analisamos diz respeito aos recursos e linguagens dos cartazes. O resultado dessa análise pode ser visto na Tabela $4 \mathrm{a}$

3 Procedimentos também encontrados por Possenti (2013), Murano (2013) e Godói (2013) resenhados anteriormente. 
v. 6 (2)

54-71

jul/dez

2016

seguir:

Tabela 4 - Recursos e linguagens utilizados

\begin{tabular}{|l|l|l|}
\hline & Qtd. & $\%$ do Total \\
\hline Linguagem não verbal & 5 & $10,0 \%$ \\
\hline Linguagem da Internet & 4 & $8,0 \%$ \\
\hline Total Sem duplicidades & 50 & $100,0 \%$ \\
\hline
\end{tabular}

A presença de procedimentos próprios da internet e o uso de imagens evidenciam que o autor é usuário frequente dessas mídias virtuais e talvez tenha a intenção de usar a imagem do cartaz em uma postagem evidenciando sua participação na manifestação. A relação entre os textos dos cartazes e as postagens nas mídias sociais fica patente, como já haviam apontado Brait; Lopes-Dugnani (2014) e Sakamoto (2013). É o que podemos ver em (13) e (14).

\section{(13) \#FORAFELICIANO}

(14)

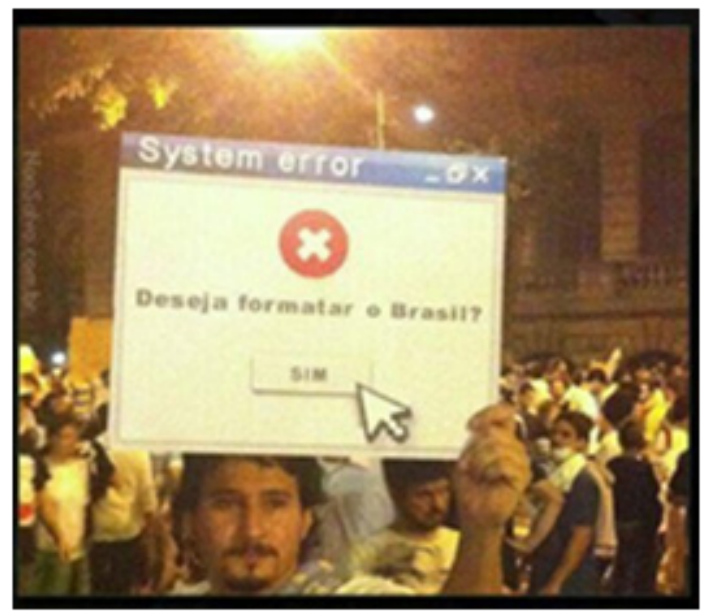

Fonte: http://www.filhovemver.com.br/os-melhores-cartazes-das-manifestacoespelo-brasil/

Definimos como "não verbal" os textos que fazem uso de imagens, fotos, desenhos e ou ilustrações utilizadas nos cartazes. Tais recursos têm suma importância na construção do sentido do texto. É o que ocorre em (14), já mencionada anteriormente, e em (15), a seguir, nos quais o verbal e o não verbal juntos colaboram para o processo de significação. Em (16), percebemos que, em alguns casos, dispensou-se o uso de linguagem verbal. 
(15)

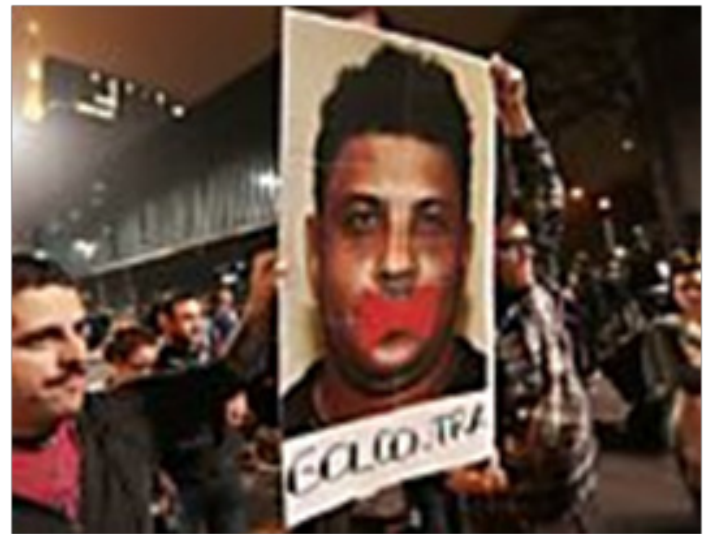

Fonte: http://fotografia.folha.uol.com.br/galerias/17182-setimo-ato-domovimento-passe-livre-em-sp\#foto-291478

(16)



Fonte:

http://fotografia.folha.uol.com.br/galerias/17182-setimo-ato-domovimento-passe-livre-em-sp\#foto-291478

Nosso trabalho também procurou avaliar as escolhas lexicais feitas nos cartazes. Em sua maioria, estes apresentam uma linguagem não formal, não se apelando muito, por exemplo, para palavrões. Como vimos no exemplo (4), que contém a expressão "busão", as gírias podem ser utilizadas de maneira livre nos cartazes. Outra característica é o uso de marcas e de nomes de produtos, sempre com boa dose de humor, em alguns casos, utilizando-se da paronomásia e outros procedimentos estilísticos, como (17), (18) e (19).

(17) Jogaram Mentos na geração Coca-Cola.

(18) Yes PAC MAN! NO PEC 37!

(19) Odeio bala de borracha joga um Halls.

Procuramos também investigar os aspectos sintáticos mais específicos dos textos de protestos recolhidos. Com esse objetivo, avaliamos os tipos de sentenças mais comuns, o que vemos a seguir. 
V. $6(2)$

54-71

jul/dez

2016

Tabela 5 - Tipos de sentenças/frases Utilizadas: nominais x simples x coordenadas $\mathrm{x}$ subordinadas

\begin{tabular}{|l|l|l|}
\hline & Qtd. & $\%$ do Total \\
\hline Frases Nominais & 10 & $20,0 \%$ \\
\hline Sentença Simples & 20 & $40,0 \%$ \\
\hline Sentenças Coordenadas & 13 & $26,0 \%$ \\
\hline Sentenças Subordinadas & 10 & $20,0 \%$ \\
\hline Total Sem duplicidade & 50 & $100,0 \%$ \\
\hline
\end{tabular}

Como podemos ver, os cartazes que recolhemos são feitos em sua maioria com sentenças de período simples, com um único verbo, assim como mostramos em (17). Ainda, se juntarmos isso às nominais, isto é, às frases construídas sem um sintagma verbal explícito, confirmamos novamente que o gênero que ora analisamos pede textos enxutos e rápidos.

Na Tabela 6, a seguir, que consolida outros procedimentos sintáticos/discursivos, observa-se a baixa produtividade de verbos no imperativo. Ainda que os textos injuntivos totalizem 34\% - Vide Tabela 2 , as estratégias para exigir ou reivindicar são sempre indiretas, sem a estrutura de uma "ordem", como podemos ver em (20).

Tabela 6 - Outros procedimentos sintáticos/discursivos

\begin{tabular}{|l|l|l|}
\hline & Qtd. & $\%$ do Total \\
\hline Usa vocativos & 4 & $8,0 \%$ \\
\hline Usa verbos no Imperativo & 5 & $10,0 \%$ \\
\hline Total Sem duplicidade & 50 & $100,0 \%$ \\
\hline
\end{tabular}

(20) Por um transporte verdadeiramente público e de qualidade.

O uso de vocativo tem baixa produtividade, mas não deixa de ser uma estratégia interessante nos cartazes. Em (21), por exemplo, buscase exigir mais salários para os professores, mas o vocativo não remete ao Secretário, ao Ministro da Educação ou a qualquer governante. É o próprio "oprimido", aquele a quem se pretende defender, a que o vocativo remete. Também interessante é a defesa de investimentos em educação em detrimento aos gastos com futebol — referência à Copa do Mundo - através do uso do vocativo "Japão", o que podemos ver em (22). Evidentemente, a mensagem não é, ao final, direcionada ao Japão.

(21) Professor te desejo um salário de deputado e o prestígio de jogador de futebol 
(22) Japão, eu troco nosso futebol pela sua educação

Por fim, nossa análise procurou investigar os atos ilocucionários (realizados pelo locutor) e os atos perlocucionário (atos que o locutor espera que seu interlocutor realize). É o que consolidamos na Tabela 7.

Tabela 7 - Matriz de Atos Ilocucionários x Atos Perlocucionários mais frequentes

\begin{tabular}{|c|c|c|c|c|c|c|c|c|}
\hline & \multicolumn{3}{|c|}{ ATO PERLOCUCIONAL } \\
\hline & $\begin{array}{c}\text { Atender a } \\
\text { revindicação }\end{array}$ & \multicolumn{2}{|c|}{$\begin{array}{c}\text { Atender à } \\
\text { Convocaça }\end{array}$} & \multicolumn{2}{c|}{ Refletir } & \multicolumn{2}{|c|}{ Total } \\
\hline $\begin{array}{c}\text { ATO } \\
\text { ILOCUCIONAL }\end{array}$ & Qtd. & $\begin{array}{c}\% \text { do } \\
\text { Total }\end{array}$ & Qtd. & $\begin{array}{c}\% \text { do } \\
\text { Total }\end{array}$ & Qtd. & $\begin{array}{c}\% \text { do } \\
\text { Total }\end{array}$ & Qtd. & $\begin{array}{c}\% \text { do } \\
\text { Total }\end{array}$ \\
\hline Aconselhar & & $0 \%$ & & $0 \%$ & 1 & $2 \%$ & 1 & $2 \%$ \\
\hline $\begin{array}{c}\text { Ameaçar/ } \\
\text { Reivindicar }\end{array}$ & 3 & $6 \%$ & & $0 \%$ & & $0 \%$ & 3 & $6 \%$ \\
\hline Convocar & & $0 \%$ & 1 & $2 \%$ & & $0 \%$ & 1 & $2 \%$ \\
\hline Declarar & & $0 \%$ & & $0 \%$ & 32 & $64 \%$ & 32 & $64 \%$ \\
\hline Questionar & & $0 \%$ & & $0 \%$ & 1 & $2 \%$ & 1 & $2 \%$ \\
\hline Reivindicar & 12 & $24 \%$ & & $0 \%$ & & $0 \%$ & 12 & $24 \%$ \\
\hline Total Geral & 15 & $30 \%$ & 1 & $2 \%$ & 34 & $68 \%$ & 50 & $100 \%$ \\
\hline
\end{tabular}

A Tabela 7, em formato de matriz, apresentou resultados interessantes que nos ajudam a compreender os protestos, cujos cartazes aqui estudamos. Como podemos ver, o mais comum é declarar algo para que o interlocutor reflita, o que é feito em $64 \%$ dos casos, como nos exemplos (23) e (24).

(23) País desenvolvido não é onde pobre tem carro, é onde rico usa transporte público.

(24) Cansei de fingir que tem uma capa de invisibilidade na sujeira do país.

Reivindicar e exigir que se atenda à reinvindicação é bem mais raro. Isso ocorre em $24 \%$ dos cartazes, como (25) e (26):

(25) O povo unido não precisa de partido.

(26) Queremos hospitais padrão FIFA.

Se juntarmos esses últimos casos aos que classificamos como "ameaçar/reivindicar", teríamos no máximo 30\% como explicitamente reivindicatórios. Nossa percepção é de que esse percentual é baixo para uma 
v. 6 (2)

54-71

jul/dez

2016

onda de protestos da dimensão como a que assistimos naquele período de 2013. Isso conta muito sobre a ideologia e a visão de mundo dessa geração. Sobre este ponto nos ateremos mais detalhadamente adiante.

\section{O que os dados nos contam?}

Seguindo a pista de Bourdieu (2003), podemos sustentar que os textos dos cartazes que aqui analisamos são produtos linguísticos produzidos a partir do habitus das novas gerações de jovens (grande maioria dos participantes) para exposição em mercado linguístico (e social) específico. Pelos dispositivos do habitus, se define "O quê" pode ser comunicado e "como" isso deverá ser escrito, no caso dos cartazes. Se a manifestação aqui é um "mercado linguístico", esta não está isolada. Está conectada com os mercados virtuais das redes sociais, o que, como vimos, pode ser percebido linguisticamente em alguns dos exemplos que analisamos (SAKAMOTO, 2013). Quem assistiu a essas manifestações pôde comprovar o uso constante de celulares e dispositivos móveis e em tempo de protesto, para postar a participação no movimento. Os cartazes foram produzidos não só para cumprir a função nas ruas, mas a de marcar a presença do participante nesse locus virtual. Foram criados para a postagem posterior.

Emnossainterpretação, o habitusdosparticipantes das manifestações apresenta as marcas das gerações da chamada "modernidade líquida", descrita por Bauman (2001). Para esses, tudo é fluido:

Como os compromissos de hoje são obstáculos para as oportunidades de amanhã, quanto mais forem leves e superficiais, menos o risco de prejuízos. 'Agora' é a palavra-chave da estratégia de vida, ao que quer que essa estratégia se aplique e independente do que mais possa sugerir (BAUMAN, 2001, p. 187).

Os resultados de nossa pesquisa evidenciam isso, que aparece na baixa frequência de verbos no imperativo, de textos injuntivos, de atos ilocucionais que remetam a "exigir" e "reivindicar" algo. E, pelo outro lado, explicam a maior presença de textos que apenas "declaram" ou "expõem" algo. Participar e, portanto, falar da própria "manifestação" é mais importante que exigir algo. Sakamoto (2013) parece ter percebido esse vínculo frágil - fluído - com uma luta mais profunda por algo.

São protestos que diríamos "líquidos", assumindo a forma com que Bauman interpreta várias facetas de nossa sociedade, e seus cartazes não poderiam ficar isentos dessa característica tão importante. 


\section{REFERÊNCIAS}

BAKHTIN, M. Os Gêneros do discurso. In: Estética da Criação

Verbal. São Paulo: Martins Fontes, 2011.

BAUMAN, Z. Modernidade Líquida. Rio de Janeiro: Jorge Zahar Editor, 2001.

BOURDIEU, P. O mercado Linguístico. In: Lisboa: Fim de Século, 2003.

Questões de Sociologia.

BRAIT, B.; LOPES-DUGNANI, B. Em cartaz, a cara e o corpo da linguagem das ruas!. In: BRAIT, B.; MAGALHÃES, A. S. (Orgs.) Dialogismo: teoria e(m) prática. São Paulo: Terracota Editora, 2014.

CASTILHO, A. T. de. Nova Gramática do Português Brasileiro. São Paulo: Ed. Contexto, 2010.

GODOI, M. A irreverência que dá cartaz. Revista Língua Portuguesa, São Paulo: Editora Segmento, agosto de 2013, Ano 8, no 94, disponível em: http:// revistalingua.com.br/textos/94/a-irreverencia-que-da-cartaz-294827-1. asp, acesso em 21 abr. 2016.

MARICATO, E. É questão urbana, estúpido. In: MARICATO, Ermínia et. al. Cidades Rebeldes - Passe Livre e as Manifestações que tomaram as ruas do Brasil. São Paulo: Boitempo e Carta Maior, 2013.

MPL. Carta de Princípios. Sem Data. Disponível em: http://saopaulo.mpl.org. br/apresentacao/carta-de-principios. Acesso em: 10 fev. 2016.

Não começou em Salvador, não vai terminar em São Paulo. In: MARICATO, Ermínia et. al. Cidades Rebeldes - Passe Livre e as Manifestações que tomaram as ruas do Brasil. São Paulo: Boitempo e Carta Maior, 2013.

MURANO, E. A linguagem dos protestos. Revista Língua Portuguesa, São Paulo: Editora Segmento, agosto de 2013, Ano 8, no 94, disponível em: http:// revistalingua.com.br/textos/94/artigo293651-1.asp, acesso em 21 abr. 2016.

POSSENTI, Sirio Leitura das ruas. Revista Língua Portuguesa, São Paulo: Editora Segmento, agosto de 2013, Ano 8, no 94, Disponível em: http://revistalingua. com.br/textos/94/leitura-das-ruas-294844-1.asp, acesso em 21 abr. 2016.

ROLNIK, R. As vozes das ruas: as revoltas de junho e suas interpretações. In: Maricato, Ermínia et. Al. Cidades Rebeldes - Passe Livre e as Manifestações que tomaram as ruas do Brasil. São Paulo: Boitempo e Carta Maior, 2013.

SAKAMOTO, L. Em São Paulo, o Facebook e o Twitter foram às ruas. In: Maricato, Ermínia et. Al. Cidades Rebeldes - Passe Livre e as Manifestações que tomaram as ruas do Brasil. São Paulo: Boitempo e Carta Maior, 2013.

VAINER, C. Quando a cidade vai às ruas. In: MARICATO, Ermínia et. al. Cidades Rebeldes - Passe Livre e as Manifestações que tomaram as ruas do Brasil. São Paulo: Boitempo e Carta Maior, 2013.

Recebido em: 18 de jul. de 2016.

Aceito em: 21 de ago. de 2016. 